\title{
ESCOLA: DISPOSITIVO DISCIPLINAR EM UMA SOCIEDADE DE CONTROLE
}

\author{
Douglas Crivelaro Pacheco
}

Universidade Estadual Paulista - UNESP, Programa de Pós Graduação em Educação, Presidente Prudente - SP, E-mail: douglas.crivelaro93@gmail.com.

\begin{abstract}
RESUMO
O modelo econômico atual é marcado pela expansão do neoliberalismo americano. Deste modelo liberal que se dedica a analisar o comportamento humano do ponto de vista da competição, destaca-se a teoria do capital humano. Nesta teoria o ser humano é entendido como homo oeconomicus, empresário de si mesmo. Para que o ser humano se entenda desta forma ele está submetido a dispositivos de poder, de acordo com os objetivos da governamentalidade vigente. $\mathrm{O}$ período pós-moderno é marcado por uma governamentalidade biopolítica orientada por razões econômicas, a chamada sociedade de Controle, na qual, de forma dissonante, encontra-se inserida a escola como dispositivo disciplinar. Este artigo busca compreender o papel da escola nesta composição de Controle, como um espaço de sujeição através do poder disciplinar. Para tal, desenvolve-se uma pesquisa bibliográfica de perspectiva exploratória.
\end{abstract}

Palavras-chave: Escola, Sociedade de Controle, Dispositivo Disciplinar.

\section{SCHOOL: DISCIPLINARY APPARATUS IN A SOCIETY OF CONTROL}

\begin{abstract}
The current economic model is marked by the expansion of American neoliberalism. This liberal model that is dedicated to analyze human behavior from the point of view of competition, it stands out the theory of human capital. In this theory the human being is understood as homo oeconomicus, entrepreneur of itself. In order for the human being to understand himself in this way he is subject to the mechanisms of power, in accordance with the objectives of the current governmentality. The postmodernity is marked by a biopolitical governmentality guided by economic reasons, the Society of Control, in which, dissonantly, school is found as a disciplinary apparatus. This article seeks to understand the role of the school in this composition of Control, as a space of subjection through disciplinary power. For this, a bibliographical research of exploratory perspective is developed.
\end{abstract}

Keywords: School, Society of Control, disciplinary apparatus. 


\section{INTRODUÇÃO}

Quando pensamos o mundo contemporâneo, pensamos em diversos avanços tecnológicos, em diversas áreas, como na medicina, nas tecnologias de comunicação, nos esportes. Todavia, apesar dos diversos avanços advindo de tal desenvolvimento, ainda nos deparamos com certas situações que a princípio parecem ultrapassadas.

Dentre estas, pensar a escola, que tão pouco se diferenciou nos últimos séculos, nos leva a diversos questionamentos. Será que ela é de fato ultrapassada? Ela ainda serve ao seu objetivo? Se sim, qual é?

Tais questionamentos podem encontrar pistas para seu esclarecimento nos escritos de Foucault, sobretudo quando ele discute os dispositivos de poder usados pelas formas de governamentalidade.

Este texto tem por objetivo pensar a Escola enquanto dispositivo disciplinar presente em uma sociedade Pós-Moderna. Para tal, faz-se necessário uma análise do contexto econômico, bem como das formas que sustentam o poder, para que se possa, questionar o papel da escola neste cenário.

\section{METODOLOGIA}

Segundo Gil (2002), pode-se compreender uma pesquisa tendo como base seus objetivos, estes podem ser exploratórios descritivos e explicativos, este texto situa-se dentro de uma perspectiva exploratória, visto que ainda transita na esfera dos levantamentos de hipóteses sobre o papel que a escola exerce sobre seus usuários inseridos na sociedade pós-moderna, evidenciando suas relações com o contexto neoliberal, a fim de afirmá-la como um instrumento disciplinar em uma Sociedade de Controle. Para tal feito, este texto, desenvolve-se como uma pesquisa bibliográfica.

A pesquisa bibliográfica é feita a partir do levantamento de referências teóricas já analisadas, e publicadas por meios escritos e eletrônicos, como livros, artigos científicos e páginas de web sites [...] com o objetivo de recolher informações ou conhecimentos prévios sobre o problema (FONSECA, 2002, p. 32).

A escolha do tema deste texto é fruto de reflexões construídas a partir das leituras elaboradas durante a disciplina intitulada Educação, poder e subjetividade: uma leitura filosófica, oferecida pelo Programa de Pós-Graduação em Educação, da Faculdade de Ciências e Tecnologia da Universidade Estadual Paulista "Júlio de Mesquita Filho" (UNESP), Campus de Presidente Prudente/SP. Tais leituras induziram o levantamento das questões sobre o papel da Escola enquanto criadora de subjetividade e instrumento para a manutenção do poder. Nesse sentido, foi dada maior ênfase aos textos de Foucault, como bibliografia primária, para em seguida buscarse desdobramentos dos conceitos trazidos por este pensador no âmbito educacional.

\section{Do liberalismo ao neoliberalismo americano}

Vivemos em um contexto de globalização do neoliberalismo americano, que se caracteriza por diferenças essenciais quando relacionado a outras formas de liberalismos, como por exemplo, o francês ou o alemão. Michel Foucault (2008, p.299) evidencia algumas dessas diferenças quando cita que:

O liberalismo americano, no momento em que se formou historicamente, [...] não se apresentou como na França a título de princípio moderador em relação a uma razão de Estado preexistente, pois são precisamente, ao contrário, reivindicações de tipo liberal, reivindicações essencialmente econômicas aliás, que foram o ponto de partida histórico da formação da independência dos Estados Unidos. 
Desta forma, o debate econômico e o político sempre estiveram atrelados nos Estados unidos. Consequentemente, há uma deliberada aversão às práticas intervencionistas, dentre as quais podemos citar o keynesianismo, programas sociais, etc. Compreende-se melhor esse modelo neoliberalista na seguinte frase: "O (neo)liberalismo, nos Estados Unidos, é toda uma maneira de ser e de pensar." (FOUCAULT, 2008, p. 301).

Quando se pensa o liberalismo clássico e o neoliberalismo americano há, todavia, uma mudança de foco. Enquanto o primeiro se dedica a compreensão do "mecanismo relacional entre coisas ou processos, do gênero capital, investimento, produção, em que, nesse momento, o trabalho se encontra de fato inserido somente a título de engrenagem" (FOUCAULT, 2008, p. 307); o segundo pensa o comportamento humano. Em outras palavras, "enquanto no liberalismo a liberdade do mercado era entendida como algo natural, espontâneo, no sistema neoliberal a liberdade deve ser continuamente produzida e exercitada sob a forma de competição." (VEIGANETO, 2011, p.38)

Deste novo modelo liberal que se dedica a analisar o comportamento humano, do ponto de vista da competição, destaca-se a teoria do capital humano. Tal teoria volta seu olhar para o trabalho, não numa análise quantitativa relacionada ao tempo, como foi feito por economistas políticos clássicos, mas sim numa apreciação qualitativa. O que importa não é quanto tempo é gasto com o trabalho, qual o seu valor, etc., mas "o problema fundamental, essencial, em todo caso primeiro, que se colocará a partir do momento em que se pretenderá fazer a análise do trabalho em termos econômicos será saber como quem trabalha utiliza os recursos de que dispõe" (FOUCAULT, 2008, p. 307). Trata-se de um cálculo, do ponto de vista do próprio trabalhador, em que o trabalho será visto como capital, adquirindo valor econômico de acordo com suas qualificações, gerando, assim, uma renda para o trabalhador.

o trabalho não é uma mercadoria reduzida por abstração à força de trabalho e ao tempo durante o qual ela é utilizada. Decomposto do ponto de vista do trabalhador, em termos econômicos, o trabalho comporta um capital, isto é, uma aptidão, uma competência; como eles dizem: é uma "máquina". (FOUCAULT, 2008, p. 309)

Desta ótica é algo concreto, composto por competências e aptidões, inatas e adquiridas, capazes de serem convertidas em renda a título de salário.

Nota-se, porém, uma peculiaridade deste capital, "a aptidão a trabalhar, a competência, o poder fazer alguma coisa, tudo isso não pode ser separado de quem é competente e pode fazer essa coisa." (FOUCAULT, 2008, p. 309). Partindo desta reflexão, passa-se a pensar o indivíduo inserido neste contexto. O ser humano é aqui entendido como homo oeconomicus, que por sua vez, é "empresário de si mesmo, sendo ele próprio seu capital, sendo para si mesmo seu produtor, sendo para si mesmo a fonte de [sua] renda." (FOUCAULT, 2008, p.311)

\section{AS GOVERNAMENTALIDADES E SEUS DISPOSITIVOS}

Vale enfatizar que com o exercício de influência do poder econômico no cenário político haverá também alterações nos dispositivos de poder. "Foucault encontrou uma terminologia adequada para designar e analisar a atividade que consiste em reger a conduta dos homens em um contexto e por meio de instrumentos estatais". (DUARTE, 2011, p.53), a chamada "governamentalidade". É a forma que se exerce esta governamentalidade que passa por transformações durante a história, todavia, não deixando de ser práticas difusas e discretas capazes da condução dos indivíduos.

Antes do surgimento da biopolítica, a sociedade era orientada pelos estados soberanos através dos dispositivos disciplinares, estes se concentravam no controle do corpo individual, com ênfase no processo de coerção; este modelo se caracteriza por entidades de confinamento, como as escolas, hospitais, prisões, etc. 
Já a biopolítica não se preocupa, somente, com os indivíduos, mas com o gerenciamento da população, por meio de políticas normatizadoras de processos biológicos, instrumentalizados por meio de cálculos estatísticos e das ciências médicas. A biopolítica

[...] pretendia normalizar a própria conduta da espécie ao regrar, manipular, incentivar e observar fenômenos que não se restringiam mais ao homem no singular, como as taxas de natalidade e mortalidade, as condições sanitárias das grandes cidades, o fluxo das infecções e contaminações, a duração e as condições da vida etc. (DUARTE, 2007, p.3)

Por fim, há uma evolução do conceito de biopolítica, e Foucault passa a analisar de que forma, as regras da economia impostas pelo neoliberalismo, já discutido, implicam em novos dispositivos de poder. Ele "interessa-se, então, pelas formas flexíveis e sutis de controle e governo das populações e dos indivíduos, tal como elas se exercem por meio das regras da economia do mercado mundializado, para além dos domínios limitados da soberania política tradicional" (DUARTE, 2007, p. 7)

Nesta biopolítica orientada pela razão econômica ocorre a dissolução do paradigma de confinamento, a dissolução da fábrica em empresa. Sobre isto Deleuze (2010, p.227) ainda afirma:

É uma mutação já bem conhecida que pode ser resumida assim: o capitalismo do século XIX é de concentração, para a produção, e de propriedade. Por conseguinte, erige a fábrica como meio de confinamento, o capitalista sendo o proprietário dos meios de produção, mas também eventualmente proprietário de outros espaços concebidos por analogia (a casa familiar do operário, a escola). Quanto ao mercado, é conquistado ora por especialização, ora por colonização, ora por redução dos custos de produção. Mas atualmente o capitalismo não é mais dirigido para a produção [...] É um capitalismo de sobre produção. Não compra mais matéria-prima e já não vende produtos acabados: compra produtos acabados, ou monta peças destacadas. 0 que ele quer vender são serviços, e o que quer comprar são ações. Já não é um capitalismo dirigido para a produção, mas para o produto, isto é, para a venda ou para o mercado. Por isso ele é essencialmente dispersivo, e a fábrica cedeu lugar à empresa.

\section{Escola: um dispositivo disciplinar}

Claro, que com a transformação das formas de governamentalidade não ocorre um absoluto abandono das anteriores. Há a manutenção daquelas tecnologias que ainda servem ao objetivo de condução da população. E dentre as diversas entidades que se mantém, uma que se torna imprescindível, e ao mesmo tempo tem um papel emblemático é a escola.

A escola permanece como resquício da chamada sociedade disciplinar, servindo à ampliação de aptidões técnico-científicas, ao mesmo tempo que familiariza o indivíduo à disciplina, e ainda exerce o papel de acumular no aluno capital humano, seguindo o princípio do homo oeconomicus.

Para pensar a escola, partiremos do conceito que Walter Kohan (2000, p.148) apresenta, As escolas são territórios de constituição de indivíduos em sujeitos, ou seja, espaços de sujeição deles a um outro pela dependência e controle instituídos pelas técnicas do poder disciplinar aí disseminadas e também sujeitos a si mesmos pela consciência e conhecimento de si que aprendem tanto pelo regime de verdade-saber reinante na escola quanto pelas tecnologias do eu por eles experimentadas.

Olhar pra a escola como este instrumento de sujeição permite entender a sua importância para todas as formas de governamentalidade, e o porquê de não a abandonar. É óbvio que há alterações no modo de trabalho da escola, mas não perda da sua essência, ou seja, a de ser este espaço de sujeição.

A escola é dos locais em que tecnologias disciplinares têm maior efeito sobre a população, uma vez que, se não todos, ao menos uma grande parte das pessoas passam por esta entidade. 0 discurso da escola favorece a disciplina, e a "[...] disciplina fabrica assim corpos dóceis. A disciplina 
aumenta as forças do corpo (em termos econômicos de utilidade) e diminui essas mesmas forças (em termos políticos de obediência)." (FOUCAULT,1977, p. 126).

Como se dá, porém, esse processo de disciplinarização? O primeiro elemento é o espacial, as escolas muitos se assemelham ao espaço prisional, organizados de modo a permitir uma constante vigilância dos alunos por parte dos professores, diretores, inspetores, "[...] a sala de aula formaria um grande quadro único, com entradas múltiplas, sob o olhar cuidadosamente classificador do professor" (FOUCAULT, 1977, p. 135).

Traz ainda o confinamento como forma de organização. Trazendo em sua estrutura arquitetônica o mesmo modelo das prisões, em salas como celas lado a lado, as grades, os muros altos que não permitem comunicação com o lado externo, refeitórios comunitários como local de encontro, entre outros fatores.

Além das questões espaciais, também a vigilância constante exercida nas escolas remete ao modelo panóptico das prisões, assim como o esquema de punições para as práticas transgressoras.

micropenalidades do tempo (atrasos, ausências, interrupções das tarefas), da atividade (desatenção, negligência, falta de zelo), da maneira de ser (grosseira, desobediência), dos discursos (tagarelice, insolência), do corpo (atitudes incorretas, gestos inconformes, sujeira), da sexualidade (imodéstia, indecência) (FOUCAULT, 1977, p. 159).

Estes elementos fazem "funcionar o espaço escolar como uma máquina de ensinar, mas também de vigiar, de hierarquizar, de recompensar" (FOUCAULT, 1977, p. 134). Deleuze ao identificar as características dos meios de confinamento, descritos por Foucault, tomando a fábrica como exemplo diz: "Foucault analisou muito bem o projeto ideal dos meios de confinamento, visível especialmente na fábrica: concentrar; distribuir no espaço; ordenar no tempo; compor no espaço-tempo uma força produtiva cujo efeito deve ser superior à soma das forças elementares."( DELEUZE, 2010, p. 223). Tal descrição poderia, facilmente, ser em relação a uma escola atual.

A discussão sobre a disciplina sempre ronda o discurso escolar, porque esta é sua missão: Disciplinar corpos em um ambiente de confinamento para que depois possam ser controlados de forma mais sútil em campo aberto. Assim a escola é como um treinamento extensivo de como se comportar num mundo regido pelo sistema econômico, cumprir horários, cumprir as tarefas, levar outras para a casa, tudo isso sem ter mais uma vigilância intensiva, mas como responsabilidade e auto cobrança adquiridas, como um vigia de si mesmo.

Esta disciplina reforçada na escola se torna um capital humano valioso quando incorporada pelo sujeito. E esta é a razão para a manutenção desta entidade, que mantém um modelo semelhante por séculos, enquanto outras entidades deste modelo disciplinar estão praticamente extintas ou sofreram fortes transformações.

Alguns autores, dentre os quais o próprio Deleuze e Veiga-Neto, como veremos, enxergam uma crise no modelo escolar, justamente no que reflete este modelo de confinamento, afirmando a sua superação em vista de novos modelos educacionais baseados nas governamentalidades de controle.

Deleuze (2010) pensa na substituição da escola nos moldes já conhecidos por um modelo de formação permanente, como uma forma de escalonar a rentabilidade do capital humano próprio do sujeito, mantendo-o sempre atualizado e justificado através do mérito próprio de sua formação constante. Para tal, não bastariam exames ou provas pontuais, mas seria necessário um controle contínuo através de avaliações permanentes, seguindo o fluxo formativo. Desta forma, as alterações observadas na mudança da fábrica para a empresa seriam também vistas "No regime das escolas: as formas de controle contínuo, avaliação contínua, e a ação da formação permanente sobre a escola, o abandono correspondente de qualquer pesquisa na Universidade, a introdução da "empresa" em todos os níveis de escolaridade" (DELEUZE, 2010, p.229). 
Já Veiga-Neto (2011), identifica três elementos que apontam este momento de crise do modelo escolar disciplinar. O primeiro diz respeito a substituição da escola como produtora de subjetividade,

Os dispositivos capazes de atingir cérebros à distância vêm disponibilizando, especialmente a jovens e crianças, um novo repertório de valores e de comportamentos, muitas vezes conflitantes com aqueles que são apresentados nos ambientes escolares. $O$ noopoder ${ }^{1}$ é extremamente positivo, ativando o desejo e funcionando pelo exemplo. Sua sutileza e ubiquidade o tornam muito forte. (VEIGA-NETO, 2011, p.48)

O segundo ponto que ele aponta como sinal de uma transformação é a relação da escola com o tempo, a escola adia os prazeres para momentos distantes, como a aprovação ao final do ano, por exemplo, contrariando uma lógica de recompensas e de interesse por satisfação imediata. O terceiro ponto se assemelha àquilo que apontava Deleuze: a necessidade da aprendizagem contínua coloca em xeque o modelo da escola atual, é preciso aprender a aprender.

Entendemos que o aprender a aprender significaria tornar-se empresário de si, colocandose num processo de gestão daquilo que, segundo Foucault, é chamado de capital humano pelo neoliberalismo. Gerir seu capital humano é buscar estratégias de multiplicá-lo. À escola caberia ensinar essas técnicas de gestão. (VEIGA-NETO, 2011, p. 51)

\section{CONSIDERAÇÕES FINAIS}

Embora alguns pensadores apontem para transformações futuras consideráveis na estrutura da escola, o que interessa é que ela tem servido, e muito bem aliás, a uma maquinaria de poder estabelecida por razões econômicas.

O discurso disciplinar encontra sua manifestação máxima na escola, sobretudo, em um momento em que este discurso se cala em outras entidades que antes eram detentoras deste discurso, como por exemplo a família. Desta forma, a concentração do poder disciplinador na escola aponta, não para sua transformação completa ou a sua dissolução, mas antes, para a sua solidificação neste papel de sujeição do indivíduo ao poder disciplinar.

É neste sentido, que não é possível vislumbrar o fim da escola, sobretudo, pensando na manutenção da ordem estabelecida, em que, apesar de ser uma Sociedade de Controle, tem-se a necessidade da construção de uma docilidade forjada pelo poder disciplinar. E é justamente esta a missão da Escola, enquanto, dispositivo disciplinar em uma sociedade de controle.

\section{REFERÊNCIAS}

DELEUZE,Gilles. Post Scriptum sobre as Sociedades de Controle. São Paulo: Editora 34, 2010.

DUARTE, André. Foucault e a Governamentalidade: genealogia do liberalismo e do Estado Moderno. In: CASTELO BRANCO, Guilherme; VEIGA-NETO, Alfredo (Orgs.). Foucault, Filosofia e Política. Belo Horizonte: Autêntica, 2011.

Sobre a biopolítica: de Foucault ao século XXI. In: Revista Cinética: Cultura e Pensamento, 2007. Disponível em: <http://www.revistacinetica.com.br/cep/ andre_duarte.pdf> Acesso em: 23 jul 2018.

FONSECA, J. J. S. Metodologia da pesquisa científica. Fortaleza: UEC, 2002.

FOUCAULT, Michel. Nascimento da Biopolítica. São Paulo: Martins Fontes, 2008

. Vigiar e punir: nascimento da prisão. Petrópolis: Vozes, 1977

1Termo cunhado por Lazzarato em referência a formas de poder que atuam modulando cérebros, memória e atenção. Tem sua raiz etimológica na palavra grega nous, geralmente entendida como alma. 
GIL, Antônio Carlos. Como elaborar projetos de pesquisa. São Paulo: Atlas, 2002

KOHAN, Walter. Subjetivação, educação e filosofia. Revista Perspectiva, v. 18, n. 34, 2000. Disponível em: <http://periodicos.ufsc.br/index.php/perspectiva/article/view/ 10454/9815> Acesso em: 26 jul 2018.

VEIGA-NETO, Alfredo. Governamentalidades, Neoliberalismo e Educação. In: CASTELO BRANCO, Guilherme; VEIGA-NETO, Alfredo (Orgs.). Foucault, Filosofia e Política. Belo Horizonte: Autêntica, 2011.

VEIGA-NETO, Alfredo. Espaços, tempos e disciplinas: as crianças ainda devem ir à escola? In: CANDAU, Vera Maria (Org.). Linguagens, espaços e tempos no ensinar e aprender. Rio de Janeiro: DP\&A Editora, 2001.

VEIGA-NETO, Alfredo. Foucault \& a educação. Belo Horizonte: Autêntica, 2003. 